\title{
Optimal levels of dietary vitamin A for reduced deformity incidence during development of European sea bass larvae (Dicentrarchus labrax) depend on malformation type
}

David Mazurais $^{\mathbf{a}, ~ *, 1, ~}$, Nomiki Glynatsi ${ }^{\mathbf{b}, 1}$, , Maria J. Darias ${ }^{\mathbf{a},}$, Stavroula Christodoulopoulou ${ }^{\mathbf{b},}$, Chantal L. Cahu ${ }^{\mathbf{a},}$, Jose-Luis Zambonino-Infante ${ }^{\mathbf{a},}$ and Giorgos Koumoundouros ${ }^{\mathbf{b},}$

\footnotetext{
a Ifremer Marine Fish Nutrition Team, Nutrition Aquaculture and Genomics Research Unit, UMR 1067. Ifremer, Technopole Brest-Iroise, BP 70, 29280 Plouzané, France

${ }^{b}$ University of Patras, Biology Department, 26500 Patras, Rio, Greece

${ }^{1}$ Authors contributed equally to this study
}

*: Corresponding author: David Mazurais, Tel.: +33 298224487; fax: +33 298224366, email address : David.Mazurais@ifremer.fr

Email addresses of all authors: dmazurai@ifremer.fr, nglinatsi@yahoo.gr, Maria.Jose.Darias.Caceres@ifremer.fr, stachristod@upatras.gr, $\quad$ Chantal.Cahu@ifremer.fr, Jose.zambonino@ifremer.fr, koumound@upatras.gr

\begin{abstract}
:
The purpose of this study was to examine the impact of graded levels of dietary vitamin A on sea bass larval performances and to determine optimal retinol levels at different larval stages to avoid specific skeletal malformations. Retinol was incorporated into larval feeds at $0,5,10,15,25,35$ and $70 \mathrm{mg}$ $\mathrm{kg}^{-1}$ dry matter (giving rise to RET0, RET5, RET10, RET15, RET25, RET35, RET70 groups, respectively). Analysis of the several types of deformities affecting the skull, vertebral column or fins of the fish were observed depending on experimental groups. On one hand, the incidence of skull malformations affecting the maxillary and premaxillary bones, dentaries, operculum, branchiostegal rays and glossohyal was lower for the RETO and RET5 groups. On the other hand, the frequency of vertebral (slight fusions and kyphosis of the anterior five vertebrae, over-mineralization and lordosis of the haemal vertebrae, the transformation of the last pre-haemal vertebra into haemal) and fin (deformations of the dorsal and anal pterygiophores, deviations of the related rays, modifications of the anatomy of the caudal supporting elements, partial to complete lack of the pelvic fins) deformities were lower for the RET5-70 groups. In the RET0 group, lower level of Hoxd-9 expression coincided with partial or complete lack of pelvic fin. Our results suggest that the optimal level of retinol for harmonious ontogenesis fluctuate along sea bass larvae development and that inadequate dietary retinol levels alters morphogenesis through the modulation of Hox gene expression, at least for the pelvic fin.
\end{abstract}

Keywords: Sea bass larvae; Skeletal development; Vitamin A; Hoxd-9 


\section{Introduction}

Skeletal deformities are a significant issue of product quality, animal welfare and costefficient production of finfish aquaculture. Their development is attributed to a variety of causative factors acting during mainly the early life stages, usually with common symptoms and probably with cooperative effects (Koumoundouros et al., 1997a; Koumoundouros et al., 1997b; Koumoundouros et al., 2001a; Koumoundouros et al., 2002; Sfakianakis et al., 2004; Sfakianakis et al., 2006b; Villeneuve et al., 2005a; Villeneuve et al., 2005b; Villeneuve et al., 2006). It is admitted that the factors implied in these disturbances have nutritional, environmental and genetic origins (Lall and Lewis-McCrea, 2007).

Several studies dealing with the impact of first feeding on fish development showed that the nutrients (phospholipid, vitamins, protein) play a central role in the appearance of skeletal malformation when they are not correctly supplied during the larval phase (Cahu et al., 2003) suggesting the importance of meeting the nutritional requirements during post embryogenic ontogenesis. Among them, vitamin A that is involved in differentiation, growth and development of cells and tissues during embryonic and postembryonic development (Clagett-Dame and DeLuca, 2002; Maden, 2000) is of crucial importance. In vertebrates, vitamin $A$, through its dietary metabolite retinoic acid (RA), has a well characterized role in the development of the central nervous system and eye (Luo et al., 2006; Maden, 2007), myelopoiesis (Gaines and Berliner, 2003), lung formation (Biesalski and Nohr, 2003), in the development of different skeletal structures such as limb and jaws (Lee et al., 2004; VieuxRochas et al., 2007; Weston et al., 2003), as well as in the specification of the anteroposterior axis of embryos (Dreyer and Ellinger-Ziegelbauer, 1996; Slack and Tannahill, 1992). The actions of RA are mediated by retinoic acid receptors (RAR $\alpha, \operatorname{RAR} \beta$ and RAR $\gamma$ ) which are expressed in most cell types (Chambon, 2005). RARs heterodimerize with retinoid $X$ receptors (RXR) to bind retinoic acid response elements (RARE) within the regulatory elements of target genes (De Luca, 1991; Pfahl, 1993) such as Hox genes that regulate embryonic patterning and organogenesis, notably limb development (Cohn et al., 1997; Mainguy et al., 2003).

In the last decade, several studies have investigated the impacts of vitamin A excess or deficiency on physiological parameters including skeletal development in different fish species (zebrafish: Géraudie and Ferreti, 1997; Japanese flounder: Takeuchi et al., 1998; Haga et al., 2002; European sea bass: Villeneuve et al. 2005a, 2006). Unbalanced vitamin A supply lead to vertebral and craniofacial malformations, growth retardation, and mortality. Based on these studies, optimum vitamin A levels have been determined by integrating malformation rates occurring during the whole ontogenetic period from first feeding to metamorphosis. Recently, Villeneuve et al. (2005a) indicated that the optimal dietary vitamin A level for the skeletal development of European sea bass was around $35 \mathrm{mg} \cdot \mathrm{kg}^{-1} \mathrm{DM}$ (mg per $\mathrm{kg}$ of dry matter). However, in order to avoid vitamin A-related malformations it is now important to identify the optimum retinol levels at the different ontogenetic phases during which each skeletal part develops.

In the current study, we examined the impact of graded levels of dietary vitamin A on sea bass larval performances (growth, survival) and morphogenesis (incidence and typology of skeletal deformities) by titrating the amount of incorporated retinol in the diet from 0 to 70 mg. $\mathrm{kg}^{-1}$ DM. By analysing skeletal deformities both at metamorphosis and at the juvenile stage, this study allowed us to determine optimal retinol levels at different larval stages to avoid specific skeletal malformation. Moreover, the mRNA expression of a member of the hox gene family (Hoxd-9) with known involvement in pelvic fin formation (Tanaka et al., 2005) is also compared between different dietary treatments to provide some indication on the effect of retinol intake on possible downstream processes. 


\section{Materials and Methods}

\subsection{Larval rearing and dietary treatments}

European sea bass (Dicentrarchus labrax) larvae were obtained at three days post hatching (dph) from the Ecloserie Marine de Gravelines (Gravelines, France). The fish were acclimated and divided into twenty one 35-I cylindroconical fibreglass tanks (2,100 larvae $\operatorname{tank}^{-1}$ ) at an initial density of 60 larvae ${ }^{-1}$. Tanks were supplied with through-flowing seawater, which had been previously filtered through a sand filter, then passed successively through a tungsten heater and a degassing column packed with plastic rings. Throughout the experiment, salinity was 35\%, the oxygen level was maintained above $6 \mathrm{mg} \mathrm{l}^{-1}$ by setting the water replacement in the tank at up to $30 \%$ per hour (flow rate: $0.181 \mathrm{~min}^{-1}$ ) and the photoperiod was $24 \mathrm{~h}$ light ( $9 \mathrm{~W}$ m-2 maximum intensity at the water surface). All procedures concerning the animals and their handling were conducted in accordance with The Code of Ethics of the World Medical Association (Declaration of Helsinki). The study was performed under the licence no. 29.021 by the French Department of Veterinary Services (Direction Départementale des Services Vétérinaires) to conduct experimental protocols and samplings on fish. Seven experimental groups (3 replicates per group) of sea bass larvae were reared at $20^{\circ} \mathrm{C}$ and fed, from 9 until $45 \mathrm{dph}$, on microparticulate diets incorporating $0,5,10,15,25$, 35 and $70 \mathrm{mg}$ of retinal per $\mathrm{kg}$ of DM. The retinol was added in the different groups as retinol acetate (Rovimix A 1000 Roche, $1000000 \mathrm{IU} / \mathrm{g}$ ) at 0, 16665, 33330, 49995, 83325, 116655, 233310 IU. $\mathrm{kg}^{-1}$ of DM respectively; ( $1 \mathrm{IU}=0.3 \mu \mathrm{g}$ of retinol). The composition of the diet is described in Table 1. Larvae were fed in excess (24/24 h) using automatic belt feeders in order to facilitate the encounter opportunity of the diet. Food intake was checked by direct observation of the larval digestive tract under a binocular microscope $1 \mathrm{~h}$ after feed distribution started. From 45 until $100 \mathrm{dph}$, fish from all different dietary groups were fed a commercial diet (Marin Start-miet AL.0, Le Gouessant, France).

\subsection{Diet analyses}

The analyses of the diets are exposed in Table 1. Protein concentration in the 7 diets was assayed following the Dumas method (Nitrogen Analyser 2000, Fisons Instruments, Nx6.25, Carlo Erba, Milan, Italy). Total lipids in diets were determined according to a slightly modified version of Folch's procedure (Folch et al. 1957), chloroform being replaced by dichloromethane. Retinol acetate in experimental diets was analysed following protocol described by Takeuchi et al., 1998. The levels of retinol acetate measured in the diets increased in an expected manner even if they were lower than that theoretically added : 3152, 9402, 20755, 34124, 69245, 89350 and 155200 IU. kg ${ }^{-1}$ corresponding to RET0, RET5, RET10, RET15, RET25, RET35 and RET70 groups, respectively. The difference observed between theoretically and measured dietary retinol has already been mentioned in previous experiments (Moren et al., 2004). Furthermore, specific analysis performed on ingredients used in the formulations (retinol acetate content in marine lecithin: $11900 \mathrm{IU} . \mathrm{kg}^{-1}$ ) revealed that the level of retinol acetate measured in microparticulate diets incorporating $0 \mathrm{mg}$ of retinol per $\mathrm{kg}$ of DM was mainly provided by marine lecithin.

\subsection{Skeletal analysis}

Survival was evaluated by counting the individuals in each tank at the end of the exposure to the different dietary conditions (larval stage, $45 \mathrm{dph}$ ). For growth and morphogenesis analysis, a random sample of 139-146 individuals was taken from each group (47-59 larvae per replicate) at $45 \mathrm{dph}$. Weights were monitored in parallel by sampling 300 larvae per group. Additional random samples (of 47-52 individuals for each tank) were taken at the juvenile stage (100 dph). Larval samples were anaesthetised (0.02\% phenoxyethanol), fixed in $5 \%$ phosphate buffered formalin (Markle, 1984) and stained for bone and cartilage (Park 
and Kim, 1984). Juvenile samples were anaesthetised, straight positioned along the longitudinal axis, frozen at $-20{ }^{\circ} \mathrm{C}$ and radiographed (Koumoundouros et al., 2000). The fork length (FL) of larvae was measured three days after their staining, on individual photographs taken under a stereoscopic microscope. The effect of retinol levels on the larval size at the end of the application of the different nutritional regimes was tested by means of KruskalWallis and Mann-Whitney U statistics (Sokal and Rohlf, 1981).

Larval samples were used for the examination of the majority of deformities which develop during the larval phase (Koumoundouros et al., 1997a; Koumoundouros et al., 1997b; Koumoundouros et al., 2001a; Koumoundouros et al., 2002; Georgakopoulou et al., 2007). Radiographies were used mainly for the study of haemal lordosis, which in sea bass develops during the early juvenile stage (Sfakianakis et al., 2006b). In total, 1098 larvae and 1053 juveniles were analysed. Differences in the deformity incidence between the different nutritional treatments were tested by the G-test (Sokal and Rohlf, 1981). Moreover, differences in vertebrae number between the different groups were tested by ANOVA with Bonferroni post-tests.

\subsection{Gene analysis}

To identify molecular actors and biological processes that contribute to severe pelvic fin deformities, the Hoxd-9 gene expression was investigated at 17, 24 and $43 \mathrm{dph}$ on group exhibiting distinct phenotypes. The Hoxd-9 expression was compared between the RET0 group which was the dietary group exhibiting the rate significantly higher of severe pelvic fin deformities and the RET35, one of the group exhibiting an absence of severe fin deformities. For each treatment, $200 \mathrm{mg}$ (wet body weight) whole larvae were collected at each sampling date, and total RNA was immediately extracted. Total RNA was extracted using TRIzol and reverse-transcribed using iScript cDNA Synthesis Kit (Bio-Rad Laboratories, Hercules, CA). Quantitative PCR analyses were performed in triplicate for each sample in a total volume of $15 \mu \mathrm{l}$ containing $5 \mu \mathrm{l}$ cDNA (dilution: $\left.10^{-2}\right), 0.5 \mu \mathrm{l}$ primers $\left(10 \mu \mathrm{mol} . \mathrm{I}^{-1}\right), 7.5 \mu \mathrm{l}$ iQ SYBR Green supermix $2 X$ (Bio-Rad Laboratories), and $2 \mu \mathrm{l}$ sterile water. For each target gene [Homeobox protein Hoxd-9 and elongation factor $1 \alpha($ ef $1 \alpha)$ ] specific complementary primers designed from previously cloned sequences are listed in Table 2. The housekeeping gene Ef1 $\alpha$ was chosen as a reference since it did not exhibit any significant variation between groups fed different dietery vitamin mix content in a previous experiment (Mazurais et al., 2008). In the present experiment, Ef1 $\alpha$ did not reveal significant differences between groups at the $5 \%$ level (data not shown). The amplification conditions were $3 \mathrm{~min}$ at $95^{\circ} \mathrm{C}$ and 45 cycles of $30 \mathrm{~s}$ at $95^{\circ} \mathrm{C}, 1 \mathrm{~min}$ at $60^{\circ} \mathrm{C}$. Real-time PCR analytical performance is detailed in Mazurais et al. (2008). IQ5 software (Biorad) was used to determine the relative quantity of the studied gene transcripts present in the different samples by $\Delta \Delta C T$ method. Differences in Hoxd-9 expression between the different nutritional treatments were tested by two way ANOVA with Bonferroni post-tests.

\section{Results}

\subsection{Larval performance}

Observation of the gut by transparency revealed that the feeds were efficiently ingested by the larvae of all groups (data not shown). Survival (around 60\%) did not significantly differ between different dietary groups (Table 3 ). Dietary retinol had a significant effect on the fork length of larvae at $45 \mathrm{dph}$, with the RET5 and RET10 groups (9402-20755 IU of analysed retinol acetate per $\mathrm{kg}$ of DM ) presenting significantly longer FL than RET0 or RET15-70 groups (3152 or 34124-155200 IU. kg $\left.{ }^{-1} \mathrm{DM}\right)$ ( $p<0.05$, Fig. 1). 


\subsection{Morphogenesis}

The different experimental groups presented a variety of skeletal deformities, affecting the skull, vertebral column or fins of the fish. Observed skull deformities affected the maxillary and premaxillary bones (pugheadness in severe and light degree), dentaries (shortening of the lower jaw in severe and light degree), operculum (inside folding), branchiostegal rays (curvature) and glossohyal (lateral or ventral transposition) (Fig. 2A-E). Vertebral deformities consisted of slight fusions and kyphosis of the anterior five vertebrae, over-mineralization and lordosis of the haemal vertebrae, as well as of the transformation of the last pre-haemal vertebra (12 ${ }^{\text {th }}$ centrum) into haemal (Fig. 2F-I). Finally, observed fin deformities concerned deformations of the dorsal and anal pterygiophores, associated or not with severe deviations of the related rays, slight (mainly slight fusion between two elements) or severe (extensive fusions, dislocations, shape alterations) modifications of the anatomy of the caudal supporting elements (epurals, hypurals, urostyle and pre-ural centra, parhypural), as well as partial to complete lack of the pelvic fins (Fig. 2J-N).

Dietary retinol had a significant effect on the development of deformities in all the body parts of sea bass $(p<0.05)$. The frequency of skull deformities was in general minimised for the RETO and RET5 groups (3152, 9402 IU. $\left.\mathrm{kg}^{-1} \mathrm{DM}\right)$, whereas in the RET10-70 groups (20755, $34124,69245,89350$ and 155200 IU. kg ${ }^{-1}$ DM) it presented a fluctuating elevation (Fig. 3). In contrast, all vertebral deformities which were developed presented a reverse response pattern, with their frequency being maximised (6-65\%, depending on the deformity type) in the RETO group (3152 IU. kg ${ }^{-1}$ DM)(Fig. 4). The most frequent vertebral deformity was the transformation of the last pre-haemal vertebra into haemal by the irregular development of a haemal spine on the $12^{\text {th }}$ centrum (Fig. 4A), finally resulting in one additional haemal vertebra (Table 4).

Fin deformities presented a varying response to dietary retinol levels. The frequency of severe dorsal-fin deformities was minimised in the RET10 group (20755 IU. kg-1 DM) (Fig. 5A), whereas the frequencies of light dorsal (Fig. 5B), light caudal (Fig. 5D) and severe pelvic deformities (Fig. 5F) were minimised in the RET5-10 groups (from 9402 to $155200 \mathrm{lU} . \mathrm{kg}^{-1}$ DM). Light anal-fin deformities presented their lower incidence in the RET5-35 groups(from 9402 to $89350 \mathrm{IU} . \mathrm{kg}^{-1} \mathrm{DM}$ ). Although dietary retinol had no effect on the total (severe and light) frequency of caudal fin deformities ( $p>0.05)$, it significantly affected their severity which was minimised in the RETO group (Fig. 5C-5D).

The development of inside-folded gill cover (2-6\%) and crossbite (0-4\%) was proved independent of the experimental conditions applied $(p>0.05)$.

\subsection{Gene expression}

Expression of Hoxd-9 gene was measured in fish from the RETO group that exhibited significantly higher deformity of pelvic fin (total or partial loss) in comparison with fish from the RET35 group. Two factors (time and diet) ANOVA analyses indicated that Hoxd-9 expression level was significantly different between the two groups $(p=0.0013$; Table 5$)$. Hoxd-9 expression was higher in the RET35 group. The differences of Hoxd-9 messenger quantities between the two groups were higher at 17 and $24 \mathrm{dph}$ than at $43 \mathrm{dph}$ (Fig. 6).

\section{Discussion}

The larval performance (weight and survival) obtained in this study is totally comparable to that obtained in previous ones (Villeneuve et al., 2006; Mazurais et al., 2008) as well as to that obtained with the live prey feeding sequence, still used in hatcheries (Person-Le Ruyet et al., 1993). The high survival (> 58\%) and growth rates (fork length $>18 \mathrm{~mm}$; wet weight $>$ $40 \mathrm{mg}$ ) at the end of the larval phase ( $45 \mathrm{dph}$ ) revealed that the experiment went well. On the basis of our growth data, low doses of retinol (groups RET5-10) seemed to induce overall the best results. On the contrary, Villeneuve et al. (2005), who mainly studied a higher range 
of dietary vitamin A levels, found that the dose corresponding to the RET35 group (in the present study) was the most appropriate to meet larval requirements. However, this finding must be balanced with the very elevated growth rates obtained in their work (three times higher to those usually observed), probably due to the quality of the spawning. This outstanding growth could have induced a higher and unusual nutritional requirement in vitamin $\mathrm{A}$, preventing in consequence any comparison with the present study.

The results of the present study suggest that the dietary retinol levels for the optimal development of European sea bass larvae depend to a great extend on the skeletal elements under consideration. The frequency of jaw and hyoid deformities was minimised for dietary retinol levels lower than 9402 IU. $\mathrm{kg}^{-1}$ DM (Fig. 3), whereas vertebral and fin elements developed better when retinol levels were equal or higher than 9402 IU. $\mathrm{kg}^{-1}$ DM (Fig. 4, Fig. 5). This result, together with the maximization of the incidence of vertebral and fin element deformities for the lowest retinol level could be considered as invalid with the theoretically expected unique optimal preferences of a given species. However, it could be easily explained if the ontogenetic scaling of sea bass skeletal elements is taken into account. In European sea bass, jaw, hyoid and branchial arches appeared up to the consumption of the vitelline and lipid reserves (after hatching and up to 6.5-7.5 mm total length, TL) (Gluckmann et al., 1999), clearly before the development of vertebrae (9-15 mm TL, Marino et al. 1993, Koumoundouros unpublished data) and fin supporting elements $(6.5-15.0 \mathrm{~mm}$ standard length, SL, for the caudal, 8.5-11.0 mm SL, for the anal, $9.0-14.0 \mathrm{~mm}$ for the dorsal and 11.3 $\mathrm{mm} \mathrm{SL}$ for the pelvic fin) (Koumoundouros et al., 2001b; Marino et al., 1993). Under this consideration the results of the present study suggest that vitamin A of maternal origin are enough to maintain the normal development of European sea bass up to the complete consumption of lipid reserves (5-8 days after the end of yolk-sac larval stage) (Koumoundouros et al., 2001b). It is therefore suggested that the larval rearing of European sea bass should initially be based on weak dietary levels of retinol, whereas in the next phases, the level of dietary retinol provided should be increased. This hypothesis, suggesting an effect of age post-hatching on the response of European sea bass larvae to dietary retinol, is furthermore supported by data obtained by Villeneuve et al., (2006) showing that the composition of diets (specially the levels of vitamin A and fatty acids) devoted to European sea bass larvae has a particularly determining effect on skeletal malformation before $13 \mathrm{dph}$.

Haemal lordosis can be considered as of the most studied skeletal deformity in European sea bass (Sfakianakis et al., 2006a). Its development has been attributed to the intensive swimming activity of juveniles as a response to the high water-current velocity in the rearing tanks (Divanach et al., 1997; Sfakianakis et al., 2006b). Vertebral resistance to the action of swimming activity during the juvenile stage (24-44 $\mathrm{mm} \mathrm{TL}$ ) is significantly increased by low water temperature during the larval stage $\left(20{ }^{\circ} \mathrm{C}\right.$ vs $15{ }^{\circ} \mathrm{C}$, up to $16 \mathrm{~mm} \mathrm{TL}$ ) (Sfakianakis et al., 2006b). In the present study, the development of haemal lordosis and vertebral overmineralization (closely related to haemal lordosis, Sfakianakis et al., 2006b) in sea bass juveniles was shown to be significantly favoured by the lack of retinol in the diet of larvae. Similarly to the action of developmental temperature (Sfakianakis et al., 2006b), this finding could be explained by the hypothesis of an impaired vertebrae development during the larval stage, which in the next juvenile stage resulted in haemal lordosis. Furthermore, this hypothesis is supported by the direct effect of the lack of dietary retinol on the morphogenesis of sea bass vertebrae, in the form of transformation of the $12^{\text {th }}$ pre-haemal vertebra into haemal (present study, Fig. $2 \mathrm{~F}$ and $4 \mathrm{~A}$ ).

The impact of dietary vitamin A levels on caudal fin development is in agreement with data obtained in zebrafish indicating dose dependant effects of retinoic acid on caudal fin regeneration (Geraudie et al., 1995; Geraudie and Ferreti, 1997). The development of fish fin passes through three main phases, positioning, initiation and outgrowth (Tanaka et al., 2005). In order to determine whether absence of the pelvic fin in fish fed incorporated retinol level of $0 \mathrm{mg} \cdot \mathrm{kg}^{-1}$ (RETO group) was due to a perturbation of the positioning phase, we compared the expression of Hoxd-9 in this group with that of RET35 group exhibiting normal pelvic fin development. This gene is specifically involved in the positioning phase of fins 
during larval stages contrary to downstream target genes of retinol such as RARs and RXRs which are not specifically expressed in a single organs or tissue during larvae development (Villeneuve et al., 2004). Real time PCR allowed us to reveal lower expression level of Hoxd9 in fish fed the lowest retinol level at 24 dph (Fig. 6). It has been shown by Tanaka et al., 2005 that Hoxd-9 expression in stickleback correlates with pelvic fin positioning and that the lack of Hoxd-9 expression at the time of pelvic fin initiation correlates with the absence of this structure in fugu (Takifugu rubripes). Based on these previous data and on personal observations indicating that pelvic fin outgrowth begins when standard length reaches 11.3 $\mathrm{mm}$ (around day 35 in our experiment) in European sea bass, the lower level of Hoxd-9 expression that we observed in the fish fed lowest retinol level at $24 \mathrm{dph}$ can probably reflect a perturbation of pelvic fin positioning responsible for the lack of pelvic fin formation in this group. This result indicating regulation of a Hox gene family member expression by retinoic acid is in agreement with previous data obtained in vertebrates (Mainguy et al., 2003). Regarding the involvement of Hox genes in many development processes (in particular patterning along the antero-posterior axis), the regulation of their expression by deficiency in retinoic acid, as observed for Hoxd-9, could have an influence on other skeletal development processes at the origin of the different malformations observed.

The results of the present study clearly demonstrated that although the development of the various skeletal parts is optimal under certain retinol dietary levels, the incidence of deformities rarely diminished to null (Fig. 3, Fig. 4, Fig. 5). Moreover, although the frequency of skull deformities was in general minimised at the lower two levels of retinol (lower than 9402 IU. $\mathrm{kg}^{-1} \mathrm{DM}$ ), in the levels higher than $20755 \mathrm{IU} . \mathrm{kg}^{-1} \mathrm{DM}$ it presented a fluctuating and not clearly dose-dependant response (Fig. 3). Finally, the effect of dietary retinol on caudal fin deformities was evident on their severity, but not on their total incidence (Fig. 5C, 5D). These findings do not weaken the results of the present study, as under the hypothesis of common symptomatology and cooperative action of causative factors (Koumoundouros et al. 2001a, Sfakianakis et al. 2006b) we could reasonably assume that a background incidence of deformities was developed in all the experimental conditions due to unknown causes. In a similar study, Sfakianakis et al. (2004) demonstrated the clear effect of water temperature on the development of caudal fin deformities in Pagellus erythrinus, from a minimum background incidence of $33 \%$ at the lower temperature tested to $75 \%$ at the higher. The common source of eggs and conditions applied in all experimental populations of the present study, as well as the triplicate repetition of each nutritional regime served well in the isolation of the effects of the background factors on our results.

To conclude, a variety of skeletal deformities was shown to develop in European sea bass as a response to dietary retinol levels in the present study. Of them, some are considered as significant deformities at a commercial level (pugheadness, short lower jaw, ventral projection of glossohyal, haemal lordosis, severe dorsal fin deformities, lack of pelvic fins), while the others concerned internal revisions of skeleton anatomy (light deformities of the dorsal and anal fins, caudal fin deformities, transformation of the $12^{\text {th }}$ pre-haemal vertebra into haemal, vertebral over-mineralisation) without any obvious effects on the external morphology of the fish (Fig. 2). Independently of their severity for fish external morphology, all the different types of skeletal deformities served well in the study of the effect of dietary retinol on the skeletal development of European sea bass, as well as on the identification of the optimum retinol levels at the different ontogenetic phases (where each skeletal part develops). On this last point, the present investigation completes previous studies performed in the same species which were focused on a reduced number of vertebal malformations observed at juvenile stages (Villeneuve et al., 2006). 


\section{Acknowledgements}

We are grateful to E. Desbruyères, G. Hortopan, C. Huelvan, H. Le Delliou, M.M. Le Gall and P. Quazuguel for their technical assistance, and to E. Georgakopoulou, A. Balzois and D. Karamanos for their involvement in skeletal analysis.

\section{Grants}

This work was, in part, supported by FINEFISH, a Collective Research Project of the sixth Framework Programme of the European Union (Contract 012451). M. J. Darias was supported by postdoctoral fellowship from the Fundación Ramón Areces (Spain).

\section{References}

Biesalski, H.K., Nohr, D., 2003. Importance of vitamin-A for lung function and development. Mol. Aspects Med. 24, 431-440.

Cahu, C., Infante, J.Z., Takeuchi, T., 2003. Nutritional components affecting skeletal development in fish larvae. Aquaculture 227, 245-258.

Chambon, P., 2005. The nuclear receptor superfamily: a personal retrospect on the first two decades. Mol. Endocrinol. 19, 1418-1428.

Clagett-Dame, M., DeLuca, H.F., 2002. The role of vitamin A in mammalian reproduction and embryonic development. Annu. Rev. Nut. 22, 347-381.

Cohn, M.J., Patel, K., Krumlauf, R., Wilkinson, D.G., Clarke, J.D., Tickle, C., 1997. Hox9 genes and vertebrate limb specification. Nature 387, 97-101.

De Luca, L.M., 1991. Retinoids and their receptors in differentiation, embryogenesis, and neoplasia. FASEB J. 5, 2924-2933.

Divanach, P., Papandroulakis, N., Anastasiadis, P., Koumoundouros, G., Kentouri, M., 1997. Effect of water currents on the development of skeletal deformities in sea bass Dicentrarchus labrax L. with functional swimbladder during postlarval and nursery phase. Aquaculture 156, 145-155.

Dreyer, C. Ellinger-Ziegelbauer, H., 1996. Retinoic acid receptors and nuclear orphan receptors in the development of Xenopus laevis. Int J Dev Biol. 40, 255-262.

Folch, J., Lees, M., Stanley, G.H.S., 1957. A simple method for the isolation and purification of total lipides from animal tissues. J. Biol. Chem 226, 497-509.

Gaines, P., Berliner, N., 2003. Retinoids in myelopolesis. J. Biol. Regul. Homeost. Agents 17, 46-65.

Georgakopoulou, E., Angelopoulou, A., Kaspiris, P., Divanach, P., Koumoundouros, G., 2007. Temperature effects on cranial deformities in European sea bass, Dicentrarchus labrax (L.). J. Appl. Ichthyol. 23, 99-103.

Géraudie, J., Monnot, M.J., Brulfert, A., Ferretti, P., 1995. Caudal fin regeneration in wild type and long-fin mutant zebrafish is affected by retinoic acid. Int. J. Dev. Biol. 39, 373-381.

Géraudie, J., Ferretti, P., 1997. Correlation between RA-induced apoptosis and patterning defects in regenerating fins and limbs. Int. J. Dev. Biol. 41, 529-532.

Gluckmann, I., Huriaux, F., Focant, B., Vandewalle, P., 1999. Postembryonic development of the cephalic skeleton in Dicentrarchus labrax (Pisces, Perciformes, Serranidae). Bull. Mar. Sci. 65, 11-36.

Haga, Y., Takeuchi, T., Seikai, T., 2002. Influence of all-trans retinoic acid on pigmentation and skeletal formation in larval Japanese flounder. Fish. Sci. 68, 560-570.

Koumoundouros, G., Divanach, P., Anezaki, L., Kentouri, M., 2001b. Temperature-induced ontogenetic plasticity in sea bass (Dicentrarchus labrax). Mar. Biol. 139, 817-830. 
Koumoundouros, G., Divanach, P., Kentouri, M., 2001a. The effect of rearing conditions on development of saddleback syndrome and caudal fin deformities in Dentex dentex (L.). Aquaculture 200, 285-304.

Koumoundouros, G., Divanach, P., Savaki, A., Kentouri, M., 2000. Effects of three preservation methods on the evolution of swimbladder radiographic appearance in sea bass and sea bream juveniles. Aquaculture 182, 17-25.

Koumoundouros, G., Gagliardi, F., Divanach, P., Boglione, C., Cataudella, S., Kentouri, M., 1997a. Normal and abnormal osteological development of caudal fin in Sparus aurata L. fry. Aquaculture 149, 215-226.

Koumoundouros, G., Maingot, E., Divanach, P., Kentouri, M., 2002. Kyphosis in reared sea bass (Dicentrarchus labrax L.): Ontogeny and effects on mortality. Aquaculture 209, 49-58.

Koumoundouros, G., Oran, G., Divanach, P., Stefanakis, S., Kentouri, M., 1997b. The opercular complex deformity in intensive gilthead sea bream (Sparus aurata_L.) larviculture. Moment of apparition and description. Aquaculture 156, 165-177.

Lall, S.P., Lewis-McCrea, L.M., 2007. Role of nutrients in skeletal metabolism and pathology in fish. Aquaculture 267, 3-19.

Lee, G.S., Kochhar, D.M., Collins, M.D., 2004. Retinoid-induced limb malformations. Curr. Pharm. Des. 10, 2657-2699.

Luo, T.L., Sakai, Y., Wagner, E., \& Drager, U.C., 2006. Retinoids, eye development, and maturation of visual function. J. Neurobiol. 66, 677-686.

Maden, M., 2000 The role of retinoic acid in embryonic and post-embryonic development.

Proc. Nutr. Soc. 59, 65-73.

Maden, M., 2007. Retinoic acid in the development, regeneration and maintenance of the nervous system. Nat. Rev. Neurosci. 10, 755-765.

Mainguy, G., In der Rieden, P.M., Berezikov, E., Woltering, J.M., Plasterk, R.H. \& Durston, A.J., 2003. A position-dependent organisation of retinoid response elements is conserved in the vertebrate Hox clusters. Trends Genet. 19, 476-479.

Marino, G., Boglione, C., Bertolini, B., Rossi, A., Ferreri, F., Cataudella, S., 1993. Observations on development and anomalies in the appendicular skeleton of sea bass, Dicentrarchus labrax L. 1758, larvae and juveniles. Aquac. Fish. Manage. 24, 445-456.

Markle, D.F., 1984. Phosphate buffered formalin for long term preservation of formalin fixed ichthyoplankton. Copeia 2, 525-528.

Mazurais, D., Darias, M.J., Gouillou-Coustans, M.F., Le Gall, M. M., Huelvan, C., Desbruyères, E., Quazuguel, P., Cahu, C., Zambonino-Infante, J.L., 2008. Dietary vitamin mix levels influence the ossification process in European sea bass (Dicentrarchus labrax) larvae. Am. J. Physiol. Regul. Integr. Comp. Physiol. 294, 520-527.

Moren, M., Opstad, I., Berntssen, M.H.G., Zambonino-Infante, J.L., Hamre, K. 2004. An optimum level of vitamin A supplements for Atlantic halibut (Hippoglossus hippoglossus L.) juveniles. Aquaculture 235, 587-599.

Park, E.H., Kim, D.S., 1984. A procedure for staining cartilage and bone of whole vertebrate larvae while rendering all other tissues transparent. Stain Technol. 59, 269-272.

Pfahl, M., 1993. Nuclear receptor/AP-1 interaction. Endocr. Rev. 14, 651-658.

Sfakianakis, D.G., Georgakopoulou, E., Kentouri, M., Koumoundouros, G., 2006a. Geometric quantification of lordosis effects on body shape in European sea bass, Dicentrarchus labrax (Linnaeus, 1758). Aquaculture 256, 27-33.

Sfakianakis, D.G., Georgakopoulou, E., Papadakis, I.E., Divanach, P., Kentouri, M., Koumoundouros, G., 2006b. Environmental determinants of haemal lordosis in European sea bass, Dicentrarchus labrax (Linnaeus, 1758). Aquaculture 254, 54-64.

Sfakianakis, D.G., Koumoundouros, G., Divanach, P., Kentouri, M., 2004. Osteological development of the vertebral column and of the fins in Pagellus erythrinus (L. 1758). Temperature effect on the developmental plasticity and morpho-anatomical abnormalities. Aquaculture 232, 407-424.

Slack, J.M., Tannahill, D., 1992. Mechanism of anteroposterior axis specification in vertebrates. Lessons from the amphibians. Development 114, 285-302. 
Sokal, R.R., Rohlf, F.J., 1981. Biometry: the Principles and Practice of Statistics in Biological Research. New York: W.H. Freeman.

Takeuchi, T., Dedi, J., Haga, Y., Seikai, T., Watanabe, T., 1998. Effect of vitamin A compounds on bone deformity in larval Japanese flounder (Paralichthys olivaceus). Aquaculture 169, 155-165.

Tanaka, M., Hale, L.A., Amores, A., Yan, Y.L., Cresko, W.A., Suzuki, T., Postlethwait, J.H., 2005. Developmental genetic basis for the evolution of pelvic fin loss in the pufferfish Takifugu rubripes. Dev. Biol. 281, 227-239.

Vieux-Rochas, M., Coen, L., Sato, T., Kurihara, Y., Gitton, Y., Barbieri, O., Le Blay, K., Merlo, G., Ekker, M., Kurihara, H., Janvier, P., Levi, G., 2007. Molecular dynamics of retinoic acidinduced craniofacial malformations: implications for the origin of gnathostome jaws. PLoS ONE. 6, e510.

Villeneuve, L., Gisbert, E., Le Gall M.M., Cahu, C.L., Zambonino-Infante, J.L., 2004. Expression and localization of some retinoid receptors during European sea bass (Dicentrarchus labrax) larvae development. Aquaculture. 242, 537-551.

Villeneuve, L., Gisbert, E., Le Delliou H., Cahu, C.L., Zambonino-Infante, J.L., 2005a. Dietary levels of all-trans retinol affect retinoid nuclear receptor expression and skeletal development in European sea bass larvae. Br. J. Nutr. 93, 791-801.

Villeneuve, L., Gisbert, E., Zambonino-Infante, J.L., Quazuguel, P., Cahu, C.L., 2005b. Effect of nature of dietary lipids on European sea bass morphogenesis: Implication of retinoid receptors. Br. J. Nutr. 94, 877-884.

Villeneuve, L.A.N., Gisbert, E., Moriceau, J., Cahu, C.L., Zambonino, J.L., 2006. Intake of high levels of vitamin $A$ and polyunsaturated fatty acids during different developmental periods modifies the expression of morphogenesis genes in European sea bass (Dicentrarchus labrax). Br. J. Nutr. 95, 677-687.

Weston, A. D, Hoffman, L.M., Underhill, T.M., 2003. Revisiting the role of retinoid signaling in skeletal development. Birth Defects Res. C. Embryo 69, 156-173. 
Table 1. Composition of the experimental microparticulate diets with graded levels of retinol

\begin{tabular}{|c|c|c|c|c|c|c|c|}
\hline Group designation & RETO & RET5 & RET10 & RET15 & RET25 & RET35 & RET70 \\
\hline \multicolumn{8}{|l|}{ Ingredients (in \%) } \\
\hline Defatted Fish meal* & 52 & 52 & 52 & 52 & 52 & 52 & 52 \\
\hline Hydrolysed fish meal (CPSP)* & 14 & 14 & 14 & 14 & 14 & 14 & 14 \\
\hline Soyabean lecithin* & 7 & 7 & 7 & 7 & 7 & 7 & 7 \\
\hline Marine lecithin* & 14 & 14 & 14 & 14 & 14 & 14 & 14 \\
\hline Vitamin mixture (without RA) ** & 4 & 4 & 4 & 4 & 4 & 4 & 4 \\
\hline Mineral mixture ${ }^{\star \star \star}$ & 4 & 4 & 4 & 4 & 4 & 4 & 4 \\
\hline Betaine & 1 & 1 & 1 & 1 & 1 & 1 & 1 \\
\hline Cellulose & 4 & 4 & 4 & 4 & 4 & 4 & 4 \\
\hline Retinol acetate : Rovimix A 1000 (IU. $\mathrm{kg}^{-1} \mathrm{DM}$ & 0 & 16665 & 33330 & 49995 & 83325 & $\begin{array}{l}11665 \\
5\end{array}$ & $\begin{array}{l}23331 \\
0\end{array}$ \\
\hline Retinol: (mg equivalent retinol. $\mathrm{kg}^{-1} \mathrm{DM}$ ) & 0 & 5 & 10 & 15 & 25 & 35 & 70 \\
\hline \multicolumn{8}{|l|}{ Analyses of the diets } \\
\hline Proteins (Nx6.25) \% DM & 61.4 & 60.8 & 61.3 & 62.0 & 62.8 & 60.9 & 61.5 \\
\hline Total lipids (\%DM) & 20.2 & 19.5 & 20.0 & 21.3 & 20.9 & 19.6 & 20.0 \\
\hline Ash (\%DM) & 13.5 & 14.0 & 14.3 & 14.6 & 13.6 & 13.9 & 14.1 \\
\hline Dry matter (\%) & 89.8 & 91.0 & 90.3 & 88.5 & 90.2 & 89.3 & 90.7 \\
\hline Retinol acetate (IU. $\left.\mathrm{kg}^{-1}\right)$ & 3152 & 9402 & 20755 & 34124 & 69245 & 89350 & $\begin{array}{l}15520 \\
0\end{array}$ \\
\hline
\end{tabular}

* All dietary ingredients were commercially obtained: fish meal (La Lorientaise, Lorient, France), hydrolysed fish meal (CPSP, Soluble Fish Protein Concentrate, Sopropêche, Boulogne sur mer, France), Soyabean lecithin (Ets louis François, Saint Maur des Fossés, France), Marine lecithin (LC60, Phosphomins ${ }^{\mathrm{TM}}$, Phosphotech, Saint Herblain, France).

** Composition/kilogram of the vitamin mixture: choline concentrate $50 \%, 200 \mathrm{~g}$; vitamin $\mathrm{E}$ (500 IU/g) $10 \mathrm{~g}$; vitamin D3 (500,000 IU/g) $0.50 \mathrm{~g}$; vitamin B3 $1 \mathrm{~g}$, vitamin B5 2 g; vitamin B1 $100 \mathrm{mg}$; vitamin B2 $0.4 \mathrm{~g}$; vitamin B6 $300 \mathrm{mg}$; vitamin C $20 \mathrm{~g}$; vitamin B9 100 mg; vitamin concentrate B12 (1 g/kg), $1 \mathrm{~g}$; biotin, $1 \mathrm{~g}$; vitamin K3 $1 \mathrm{~g}$; meso-inositol $30 \mathrm{~g}$; cellulose, 7321 g.

*** Composition/kilogram of the mineral mixture: $90 \mathrm{~g} \mathrm{KCl}, 40 \mathrm{mg} \mathrm{KIO}, 500 \mathrm{~g} \mathrm{CaHPO}_{4} 2 \mathrm{H}_{2} \mathrm{O}$, $40 \mathrm{~g} \mathrm{NaCl}, 3 \mathrm{~g} \mathrm{CuSO}_{4} 5 \mathrm{H}_{2} \mathrm{O}, 4 \mathrm{~g} \mathrm{ZnSO}_{4} 7 \mathrm{H}_{2} \mathrm{O}, 20 \mathrm{mg} \mathrm{CoSO} 47 \mathrm{H} 2 \mathrm{O}, 20 \mathrm{~g} \mathrm{FeSO}_{4} 7 \mathrm{H}_{2} \mathrm{O}, 3 \mathrm{~g}$ $\mathrm{MnSO}_{4} \mathrm{H}_{2} \mathrm{O}, 215 \mathrm{~g} \mathrm{CaCO}_{3}, 124 \mathrm{~g} \mathrm{MgSO}_{4} 7 \mathrm{H}_{2} \mathrm{O}$, and $1 \mathrm{~g} \mathrm{NaF}$.

Table 2. Oligonucleotide primers used in real-time PCR

\begin{tabular}{lll}
\hline Genes & Accession Number & Primers \\
\hline Hoxd-9 & FJ262537 & F: CAGGGTTGTTTGGGTCAAGT \\
& & R: AAGCGACCAAAGAGCACAGT \\
\hline Ef1 $\alpha$ & AJ866727 & F: GCTTCGAGGAAATCACCAAG \\
& & R: CAACCTTCCATCCCTTGAAC \\
\hline
\end{tabular}


Table 3. Survival of European sea bass larvae to $45 \mathrm{dph}$ fed diets with different retinol content

\begin{tabular}{llllllll}
\hline Group & RET0 & RET5 & RET10 & RET15 & RET25 & RET35 & RET70 \\
\hline Survival (\%) & 63 & 60.6 & 63.2 & 67.8 & 79 & 58.8 & 72.1 \\
\hline
\end{tabular}

Table 4. Mean (SD) count of haemal and pre-haemal vertebrae in normal fish, and in fish with transformed pre-haemal vertebra $(\mathrm{prH}-1)$. Counts include urostyle. $\mathrm{n}$, number of fish examined in each category. Means with the same superscript are significantly different $(p<0.05)$. Means with low $n(2-4)$ were not included in the statistical analysis

\begin{tabular}{|c|c|c|c|c|c|c|}
\hline \multirow[t]{2}{*}{ Group } & \multicolumn{2}{|c|}{ Haemal Vertebrae } & \multicolumn{2}{|c|}{ pre-Haemal Vertebrae } & \multicolumn{2}{|c|}{$\mathrm{n}$} \\
\hline & Normal & prH-1 & Normal & prH-1 & Normal & prH-1 \\
\hline RETO & $13.4^{1}(0.5)$ & $14.3^{1}(0.4)$ & $12.0^{3}(0.1)$ & $11.0^{3}(0.0)$ & 51 & 102 \\
\hline RET5 & $13.3^{2 a-d}(0.4)$ & $14.2^{2}(0.4)$ & $12.0^{4}(0.1)$ & $11.0^{4}(0.0)$ & 138 & 16 \\
\hline RET10 & $13.5^{b}(0.5)$ & $13.8(0.5)$ & $12.0(0.0)$ & $11.0(0.0)$ & 149 & 4 \\
\hline RET15 & $13.4(0.5)$ & $13.5(0.7)$ & $12.0(0.1)$ & $11.0(0.0)$ & 162 & 2 \\
\hline RET25 & $13.4(0.5)$ & & $12.0(0.0)$ & & 146 & \\
\hline RET35 & $13.6^{c}(0.5)$ & & $12.0(0.1)$ & & 156 & \\
\hline RET70 & $13.6^{d}(0.5)$ & $14.0(0.0)$ & $12.0(0.1)$ & $11.0(0.0)$ & 157 & 2 \\
\hline
\end{tabular}

Table 5. Significance of combined effects of different retinol contents ( 0 and $35 \mathrm{mg}$ incorporated retinol per $\mathrm{kg}$ of $\mathrm{DM}$ ) and time (sampling point) as determined by two-way ANOVA analysis of the data in fig. 6 for Hoxd-9 expression

\begin{tabular}{lllllll}
\hline & \multicolumn{2}{l}{ Retinol content } & Time & \multicolumn{2}{l}{ Interaction } \\
\hline & $P$ value & $F$ value & $P$ value & $F$ value & $P$ value & $F$ value \\
\hline Hoxd-9 expression & 0.0013 & 17.41 & 0.56 & 0.61 & 0.27 & 1.43 \\
\hline
\end{tabular}




\section{Figures}

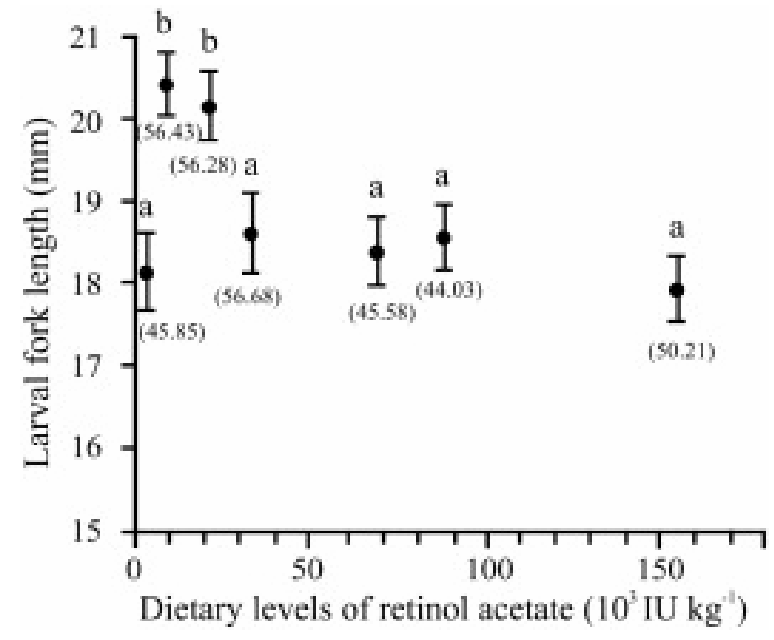

Figure 1: Effect of dietary levels of retinol on larval European sea bass fork length (FL) at 45 dph. 139-146 individuals per group were analyzed for length determination. Different letters indicate significant differences $(p<0.05)$. Bars equal to \pm 2 SE. Numbers in brackets indicate the weight in $\mathrm{mg}$. Weight were determined from 300 larvae per group. The values in $\mathrm{x}$-asis represent the levels of retinol acetate measured in the diets $(3152,9402,20755,34124$, 69245, 89350 and 155200 IU. $\mathrm{kg}^{-1}$ corresponding to RET0, RET5, RET10, RET15, RET25, RET35 and RET70 groups, respectively). 

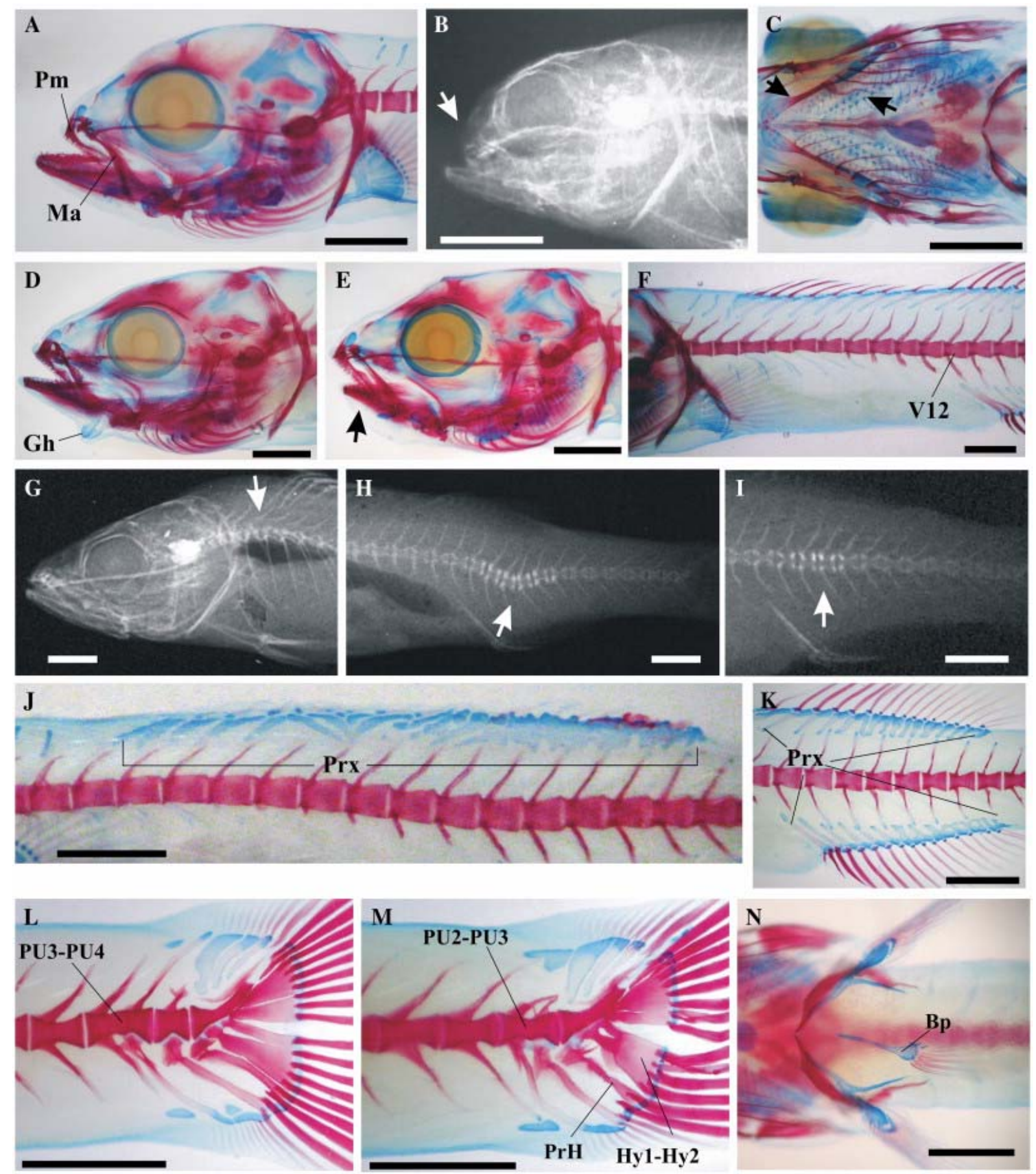

Figure 2: Main skeletal deformities developed in European sea bass larvae (stained specimens) and juveniles (x-rays). A, deformed maxillaries (Ma) and pre-maxilaries (Pm). B, pugheadness. $C$, curved and missing branchiostegal rays. $D$, ventral transposition of the glossohyal (Gh). E, shortening of the lower jaw. F, transformation of the last pre-haemal vertebra $\left(12^{\text {th }}\right.$ centrum, V12) into haemal. $G$, light kyphosis of the anterior vertebrae. $H$, haemal lordosis. I, over-mineralization of the haemal vertebrae. J, severe deformities of the dorsal fin. K, light deformities of the dorsal and anal fin pterygiophores (Prx). L and M, light and severe deformities of the caudal supporting elements (PU2-PU4, preural centra 2-4; Hy1-Hy2, hypurals 1 and 2; $\mathrm{PrH}$, parhypural). $\mathrm{N}$, partial lack of the pelvic fins (Bp, basipterygium). Scale bars equal to 1 or $5 \mathrm{~mm}$ for the stained larvae or x-rayed juveniles, respectively. 

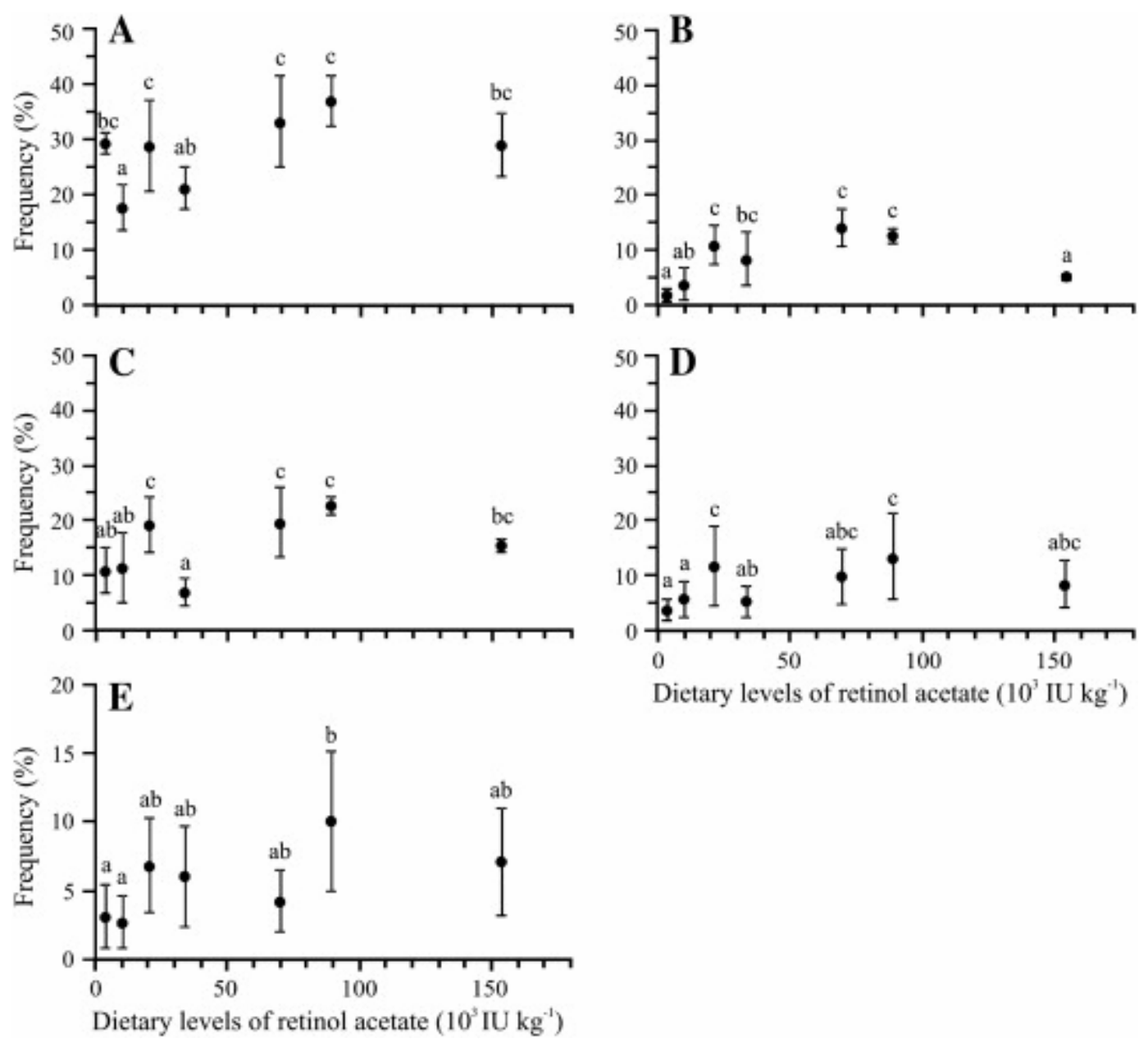

Dietary levels of retinol acetate $\left(10^{3} \mathrm{IU} \mathrm{kg}^{-1}\right)$

Figure 3: Effect of dietary levels of retinol on the development of skull deformities in European sea bass. A. Total malformations of the upper jaw in larvae. B. Severe pugheadness in juveniles. C. Deformed branchiostegal rays in larvae. D. Deformed hyoid arch in larvae. E. Short lower jaw in larvae. Each point represents the mean frequency of three replicates. In each replicate, 47-59 individuals were examined. Bars equal to $\pm 1 \mathrm{SE}$. Different letters indicate significant differences $(p<0.05)$. The values in $x$-asis represent the levels of retinol acetate measured in the diets $(3152,9402,20755,34124,69245,89350$ and 155200 IU. $\mathrm{kg}^{-1}$ corresponding to RET0, RET5, RET10, RET15, RET25, RET35 and RET70 groups, respectively). 

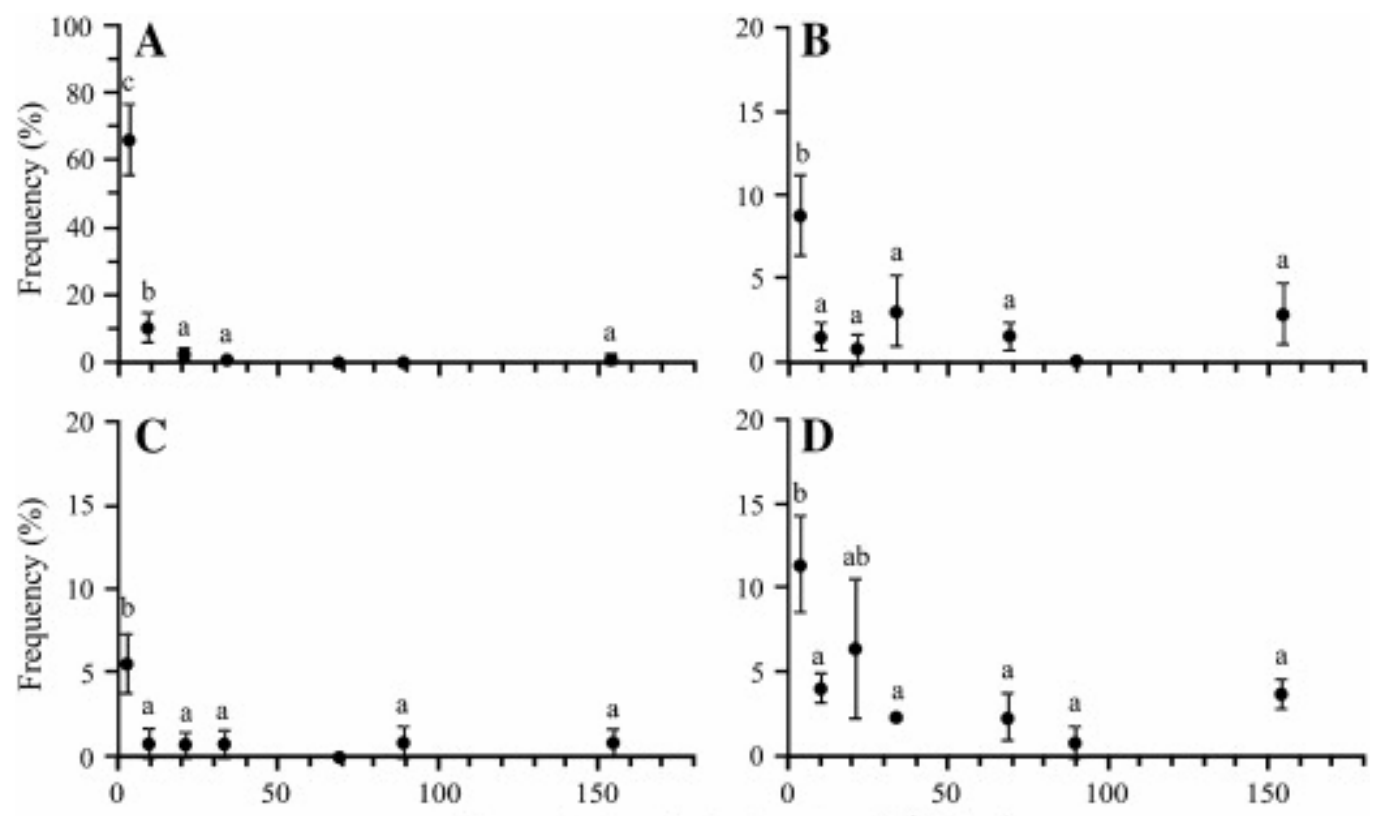

Figure 4: Effect of dietary levels of retinol on the development of vertebral deformities in European sea bass. A. Transformation of the $12^{\text {th }}$ pre-haemal vertebra to haemal (in larvae). B. Deformations of the anterior five vertebrae (in juveniles). C. Haemal lordosis (in juveniles). D. Over-mineralization of haemal vertebrae (in juveniles). Each point represents the mean frequency of three replicates. In each replicate, 47-59 individuals were examined. Bars equal to \pm 1 SE. Different letters indicate significant differences $(p<0.05)$. The values in $x$-asis represent the levels of retinol acetate measured in the diets $(3152,9402,20755,34124$, 69245, 89350 and 155200 IU. $\mathrm{kg}^{-1}$ corresponding to RET0, RET5, RET10, RET15, RET25, RET35 and RET70 groups, respectively). 

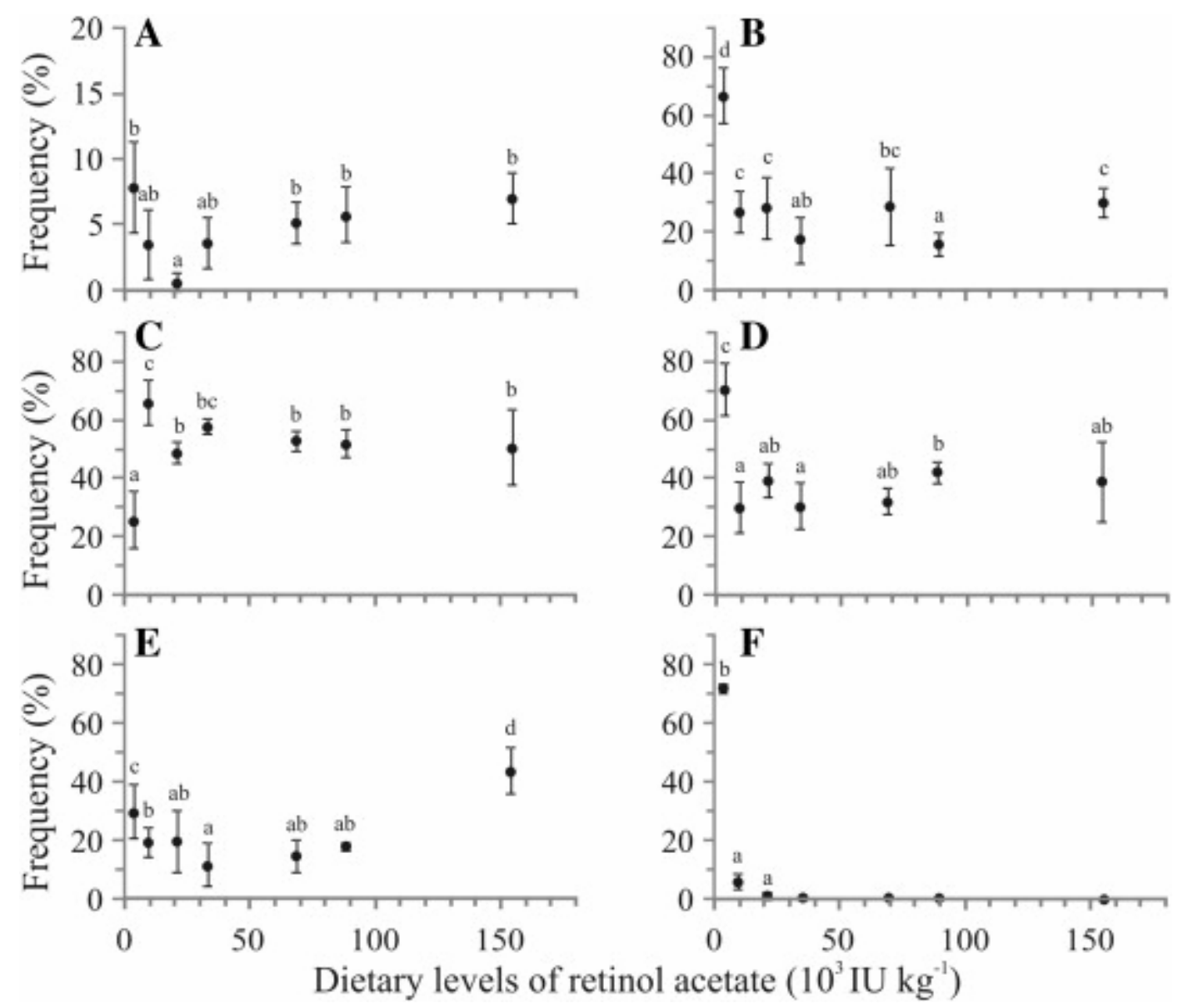

Figure 5: Effect of dietary levels of retinol on the development of fin deformities in sea bass larvae. A. Severe deformation of the dorsal fin. B. Light deformation of the dorsal fin. C. Severe deformation of the caudal fin. D. Light deformation of the caudal fin. E. Light deformation of the anal fin. F. Severe deformation of the pelvic fins. Each point represents the mean frequency of three replicates. In each replicate, 47-59 individuals were examined. Bars equal to \pm 1 SE. Different letters indicate significant differences $(p<0.05)$. The values in $\mathrm{x}$-asis represent the levels of retinol acetate measured in the diets $(3152,9402,20755$, 34124, 69245, 89350 and 155200 IU. $\mathrm{kg}^{-1}$ corresponding to RET0, RET5, RET10, RET15, RET25, RET35 and RET70 groups, respectively). 


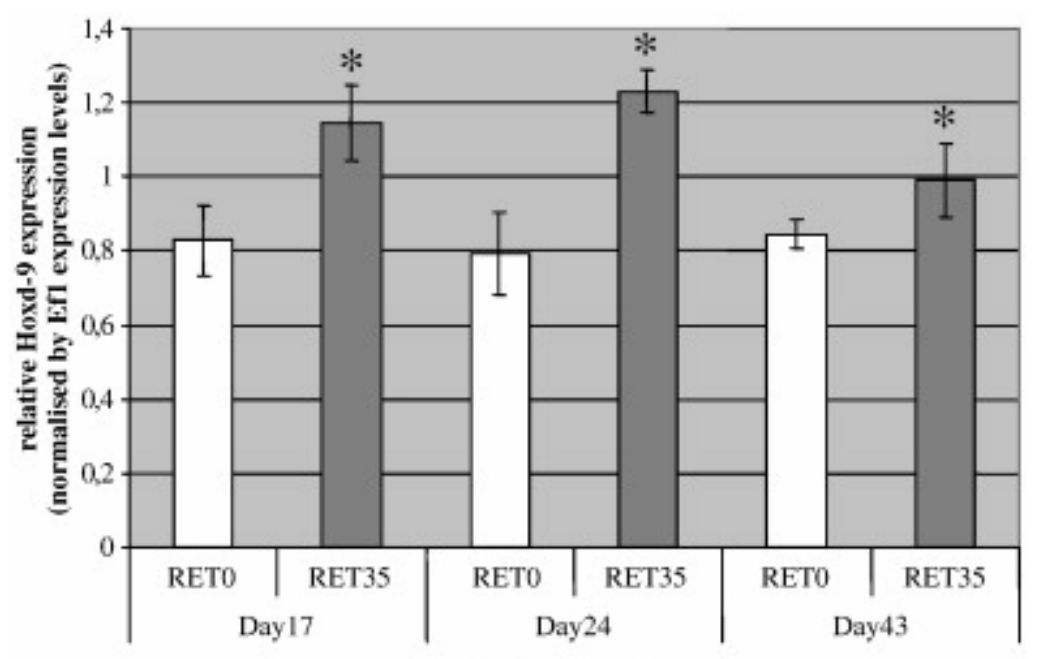

Dietarygroups

Figure 6: Relative expression of Hoxd-9 gene in whole larvae extracts from European sea bass fed 3152 and $89350 \mathrm{IU}$ retinol acetate per Kg DM (RET0 and RET35 groups respectively) at 17, 24 and $43 \mathrm{dph}$ (bars equal to $\pm 1 \mathrm{SE}$; *: significantly different as determined by two-way ANOVA with Bonferroni post-tests, $p<0.05$ ). 